\title{
Ecological Values amid Local Interests: Natural Resource Conservation, Social Differentiation, and Human Survival in Honduras*
}

\author{
Brian J. Gareau \\ Department of Sociology \\ University of California, Santa Cruz
}

\begin{abstract}
AвSTRACT Local peoples living in protected areas often have a different understanding about their natural space than do non-local groups that promote and declare such areas "protected." By designing protected areas without local involvement, or understandings of local social differentiation and power, natural resources management schemes will likely be unsuccessful. Protected area Cerro Guanacaure in southern Honduras has been subject to many development projects, most of which have failed, and the local inhabitants observe that degradation of natural resources continues. However, this case study shows that this does not mean locals view natural resources simply in an individualistic, utilitarian way. They also see their surroundings in an ecological way, and a sociocultural way. This assessment is based upon in-depth interviews with local leaders and 208 fixed format interviews of park inhabitants in Cerro Guanacaure.
\end{abstract}

Studies show that the very declaration of natural space as "protected" can lead to a heightened deterioration of natural resources rather than to their sustained maintenance. For example, Slater explains how biological reserves in Amazonia underwent this phenomenon: "Intended to shore up nature's bounty from would-be-intruders, some of the projects actually threatened long-standing equilibrium between the human and the nonhuman worlds" (1995:115; see also Cronon 1995; Liu et al. 2001). This, in part, may be caused by a lack of coherence between local understandings and practices and non-local understandings, but it also involves the opportunities available to local

* Direct correspondence to Brian J. Gareau, Department of Sociology, University of California, Santa Cruz, CA 95064, (831) 359-6709, bgareau@ucsc.edu. This is the revised version of a paper that received a commendation in the 2005 Worldwide Writing Competition for Junior Sociologists of the International Sociological Association and was originally presented at the Junior Sociologists Workshop of the XVI World Congress of Sociology, Durban, South Africa, July 20-29 2006. Partial funding was provided by the National Science Foundation (NSF) Grant No. SES-0548370. Thanks to Wally Goldfrank, Ben Crow, Melanie DuPuis, Peace Corps Honduras, and the people of Cerro Guanacaure for their support of this research. I am also grateful for suggestions offered by three anonymous reviewers of Rural Sociology. This paper is dedicated to the memory of Jessica Roy (1976-2004), a UCSC Sociology graduate student who died in Kenya while researching gender and development. 
peoples. By using the phrase "non-local,' I refer to outside agencies, institutions, and governments (both host-national and foreign) that have the power to declare natural areas protected and to enforce the provisions attached to areas with a protected status.

Some researchers have demonstrated that local peoples often have a different understanding about their natural space than do outside groups that promote and declare areas "protected" (e.g., Guha and Martinez-Alier 2000; Peluso, Humphrey, and Fortmann 1994; Pfeffer, Schelhas, and Day 2001; Watts and Peluso 2001). By putting limits on resource use devoid of local understanding and need, non-local groups frequently create a new set of complexities for near-subsistence cultures to endure that, in turn, leads to further resource degradation. Indeed, the cause of resource degradation is more than lack of understanding, or the insertion of an abstract concept or "ecological value" from the industrialized North. Rather, degradation of resources is likely linked to a lack of opportunities to survive in ways that would sustain the resources upon which people depend for survival. Access to resource rights, economic opportunity, and social acceptance of alternatives are all important factors often excluded from exogenously derived resource conservation schemes. These locally powerful socioeconomic forces likely contribute strongly to the efficacy of resource protection provisos (Geisler 2001; Walton 1992).

Other researchers emphasize the need to strengthen local participation in conservation efforts in order to make such efforts more effective. Such views stress that full local participation would produce more effective biodiversity conservation schemes that are legitimized by local communities, thus enhancing the governance of such efforts, and ensuring a more just allocation of its benefits (Brechin et al. 2002; Buck et al. 2001; Christiansen and Dinerstein 2001; Margerum 2001). However, efforts to increase participation need to acknowledge the socially differentiated structure of communities. Blanket participation is not enough, as powerful groups often can influence project schemes and shape them to their own benefit (Escobar 1996; Peet and Watts 1996; Sachs 1993; Selznick 1984). In order to create more sustainable and socially just society-environment-or, socionatural à la Swyngedouw (1999)-relationships, both participation and an acknowledgment of the social differentiation of power are important components that merit close consideration.

Using a case study conducted in Cerro Guanacaure, a protected area in southern Honduras, I provide a preliminary picture of how natural resource management initiated by outsiders likely failed to impede the 
degradation of an important cluster of watershed headwaters. ${ }^{1}$ In-depth and fixed format interviews with community members reveal a history of resource management initiated by outside agencies. The majority of community members perceive that certain natural resources remain in a degraded state. Second, I demonstrate that local peoples of Guanacaure have an acute understanding about the importance of their area, both in a 'natural' or ecological sense and a sociocultural sense. Responses to a survey of 208 residents stress concerns about the decline in natural resources, but also their importance as a part of their culture and livelihoods. This suggests that the people interviewed in Guanacaure value their homeland in a predominantly ecological way, one that even has similarities to certain First World ecological views presented by international development institutions. Family, vegetation, water, and climate in general are all considered the "most important" aspects of their homeland. The ecological view of local people suggests that declaring a certain area "protected," in itself, will neither sustain nor destroy resources, because the importance of resources is already evident. Rather, the destruction of natural resources points to the failure of institutionally derived resource protection plans to provide a socioecological framework that improves, and makes sustainable, the people-nature relationship in this area.

Pfeffer et al. (2001) and others (e.g. Brandon 1998; McMichael 2003) observe that the concept of national parks, conserving natural spaces within spatial and legislative boundaries, is often a First World phenomenon. Protected areas are frequently created and managed by outsiders with values and goals that are different from those held by people living in protected areas. This may be one of the main reasons for failure in natural resource conservation; it presents a potential clash between local and non-local values and knowledge. For instance, Pfeffer et al. (2001:384) propose that, by codifying First World park protectionism as ecological, local strategies to survive became nonecological in both value and action. In other words, a First World conceptualization of ecological values is imposed on local areas that contain alternative visions of ecology. This might deny the consideration local people give to their resources, their "natural space," to be other than a means to a tangible end. The First World conceptualization of ecological values also implies that a vast gap exists between the global environmental view and the local view held in protected areas in

1 "Watershed" is used in this article to denote the land that makes up the drainage area of streams. The headwaters are the source and upstream waters of watersheds, which are important for various ecological processes (Peterson et al. 2001). 
the global South, when in fact the differences are likely rooted in the sociocultural and ecological situatedness where the environment is valued and methods for maintaining the environment unfold. Following Pfeffer et al. (2001) the case study below examines the local reality of social conditions, the demand for natural resources, the institutions involved in resource protection, and how locals view their environment ecologically vis-à-vis global ecological values of preservation.

Moving beyond Pfeffer et al., the present case study will demonstrate that local attitudes towards the surrounding environment reflect more than utilitarian desires of "accumulating wealth" (2001:384). Indeed, communities located in protect areas could not survive while maintaining an ecological value sphere of preservationism. Interviews reveal that their concern for the surrounding environment extend beyond communities' concerns for improving their own condition. Additionally, interviews demonstrate that park management policies that ignore discrepant worldviews do more than instigate resistance from local communities; they do so in ways that highlight the differentiation among groups within the protected area. In this case, local power interests and ecological worldviews are constituted in a way that differentiates community members both internally and (as Pfeffer et al. [2001] demonstrate) from the professed aims of exogenously contrived park management schemes. Such concrete, locally powerful aspects of protected area paradigms shed light on the specific problems facing natural resource management in inhabited areas. I will later return to a discussion of the importance of local involvement in park management to accommodate the needs of local communities in globalized ecological protection schemes.

\section{Globalizing Protected Areas}

When considering Honduras as the example, it is easy to concur with the notion that protected areas in the Third World are highly subjected to globalized definitions of environmentalism. In Honduras, global environmental funds are often the virtual backbone of natural resources management, often dictating what should be protected. Global funds frequently provide most of the means necessary to implement a management scheme. During the period in which I worked in Choluteca, the southern-most department of Honduras, COHDEFOR (the Honduras Forestry Service) was so bound to outside funding that the COHDEFOR employees relied on it for even simple expenditures, like vehicle fuel and lodging. The COHDEFOR employees complained 
that their paychecks were not substantial enough to pay for these things. This is more important than it may first seem. Ebrahim (2003) shows clearly the strong relation between the shaping of particular ideas and the sources of externally-funded NGOs in Gujarat, India. Funding sources influence virtually everything an NGO does, from standard activities (documentation patterns, project monitoring, etc.) to how NGOs reflect upon their own work (Ebrahim 2003:144-148).

Global environmental groups can play powerful roles in the declaration and management of protected areas, national parks, biospheres, etc. By providing most of the funding, training, researchers (and even vehicles, fuel, rent, etc.), these groups are able to influence the definitional context of environmentalism. They are able to embed into the host-national management agenda the global definitions of what it means to protect an area. In the global arena, this means, as Pfeffer et al. point out, placing "a premium on wilderness preservation" (2001:384). There is little room for understanding exceptions to this rule. The exception becomes quite problematic when it involves human beings who live in the areas targeted for protection.

Protected areas inhabited by human communities are unique in that they challenge the globalized environmental agenda as can no other scenario. They pose a problem, because the fact that nature cannot be preserved, or remain in a static state, is most evident here. Humans alter the environment in countless ways. When they inhabit protected areas, their very behavior (farming the land, cutting branches for firewood, digging holes to make water catchments, building/improving roads, harvesting fruits, etc.) contradicts most globalized definitions of preservation. Globalized definitions of preservation demand that nature remain isolated from anthropogenic activity. Globalized definitions of preservation encapsulate fetishized interpretations of nature as separate from human activities. As Cronon (1995:86-87) states, "these peculiarly American ways of thinking about wilderness encourage us to adopt too high a standard for what counts as "natural."' In other words, the fetishized interpretation of nature that drives global environmentalism is a social construction that often conflicts with the local reality of resource management. This is why conflicts arise when the global environmental agenda encounters a scenario where humans are an obvious part of nature; humans just do not fit the global, fetishized characterization.

Pfeffer et al. (2001:384) state, "This [globalized environmental] model ... asserts the inherent value of natural resources, as opposed to focusing narrowly on their utility in accumulating wealth." Here, Pfeffer et al. imply a dichotomy between a globalized "ecological value sphere" that values natural resources inherently, and locally constitut- 
ed values, which focus more on what nature can provide for locals. Drawing on Lipschutz and Mayer (1996), the authors stress that this impasse may be overcome by establishing rules of natural resource protection that are accepted as legitimate by both local and non-local groups (Pfeffer et al. 2001:385). The evidence that I present in this paper contests Pfeffer et al.'s interpretation of local values as narrowly utilitarian, but it supports the need for natural resource management rules legitimated by those subjected to such rules. As the case study below demonstrates, locals who make their living out of 'the wilderness' also place a primacy on the ecological aspects of their lives, but not on preservation, per se, and certainly not on the severance of those aspects from human activity. Humans residing in protected areas understand that they can not preserve themselves. By placing limits on the ways inhabitants of protected areas are allowed to live in their homelands, park management can undermine their way of life. Problems arise when the protected area concept excludes prior human use and livelihoods, when developing agencies assume that wilderness exists, where in fact there is none. Left with no alternative, locals will "bend the rules," finding ways to exist within the constrictive system. If the global environmental goal is, in fact, ecological sustainability and not preservation, then including local participation in conceptualizing and solving local problems in natural resource management would be a step in the right direction.

Pfeffer et al. (2001:384) provide an interesting conception of local resistance to the global "ecological value sphere," a worldview that places strong importance on preservation over subsistence livelihoods in protected areas. Local values are smothered by the global agenda to preserve natural resources, which in turn causes locals to react by adopting one or a combination of resistance strategies (pp. 386-7). The types of resistance are not important for this paper. What is important is the notion that local peoples will find ways to appropriate certain tools in order to legitimize actions that allow them to survive even in areas with protected status. Although local peoples may demonstrate ecological concerns for their surroundings, their perceptions on what constitutes primary and secondary forest, fallow farmland, and the like will change over time in order to enhance their survival under unsustainable living conditions.

These resistance strategies, however, take on forms that are connected to the level of social differentiation that exists among community members within the protected area. While this case study provides empirical evidence that park inhabitants have a strong endogenous concern for the environment, it also demonstrates that 
they have a differential desire to work on resource conservation efforts due to the design of such projects. To further Pfeffer et al.'s analysis, one must analyze the history of local agencies, changes in resource demand over time, and local responses to these changes with an understanding of the different social conditions in which community members live. Park declaration (and the funding that accompanies it) affects community members differently based upon their different socioecological living conditions.

The question is, how can resource degradation be avoided? One element is to include local inhabitants in decision making processes on what constitutes "resource degradation" in the first place. Protected areas inhabited by humans illustrate the need for more locally deliberated definitions of natural resource use, ecology, and conservation. Additionally, it seems imperative to improve resource rights and the economic stability of local communities, something Cerro Guanacaure has experienced successfully, if in a very small way (see Gareau 2004). Broadening the globalized worldview to acknowledge situations where natural space is inhabited by humans would also help, as Pfeffer et al.'s (2001) assessment suggests (see also Brandon 1998). Yet, local views are often ignored. Instead, an ineffective dialectical debate persists between locals and non-locals, one that often continues the destruction of natural resources and the lowering of the quality of life for local peoples.

The next section will provide a background for the area of study, the Honduran protected area Cerro Guanacaure, and evidence for my core argument that the exclusion of local peoples' material needs and ecological understandings from the decision-making process results in ineffectual protected area management. Second, I will show how the ecological concerns of locals and many globalized environmental groups are often compatible. The problem is that local peoples are not presented with sensible alternatives to resource degradation vis-à-vis a host of locally experienced socioeconomic difficulties. The conclusion will repeat my claim that local inhabitants need to be included in practical decision making processes of protected area management in order to avoid the unnecessary diminishment of natural resources and destruction of local peoples' homelands.

\section{Background: Honduras' Protected Areas}

In 1975, the Honduran government nationalized the timber industry, creating the Honduran Forestry Service (COHDEFOR) (Norsworthy and Barry 1994). This process was carried out so that foreign investors and a few national industrialists could not reap the benefits of what 
many nationals considered a Honduran natural resource. This process monopolized the industry, as only the government could appoint licensing of sawn wood. Unfortunately, whereas COHDEFOR was originally designed to oversee a decrease in environmental deterioration, it actually perpetuated its increase. COHDEFOR regularly authorized timber cutting based on politics rather than concern for the environment, with no corresponding reforestation plan. Due to corruption (Norsworthy and Barry 1994), but also due to global pressure from the US Agency for International development (Jackson 2005), in 1985 COHDEFOR began a privatization process. Yet, privatization has only led to leniency in timber licensing, with privatized sawmills gaining control over important tributary areas (Norsworthy and Barry 1994:144-145). As a result, logging regulations are often ignored, even in protected areas.

In 1990, the Honduran legislature passed a municipalities law of protected area management, and in its declaration COHDEFOR gave up some of its legal jurisdiction over forested areas. Suddenly, smalltown mayors and municipal governments were in charge of forestry management within their respective boundaries. Critics argue that these parties have neither "the resources nor the clout to oversee influential private concerns active in the timber industry" (Norsworthy and Barry 1994:145-6).

Honduras was the last of the Central American countries to create a national parks system; its first national park, La Tigra, was established in 1979. As of 1996, there were 156 potential, proposed, and protected areas in Honduras, of which approximately 100 were officially protected (Marineros and Gallegos 1998:25). Though the number is high, the level of support provided for each area is not. The lack of biodiversity information, coupled with modest political and governmental support, has led to little credibility in the country's ability to protect its natural spaces. According to Marineros and Gallegos (1998:25, author's translation), "140 areas, which include the actual forested areas that COHDEFOR considers and new preliminary areas, have conservation potential within the context of the so-called Mesoamerican Biological Corridor, promoted by the Central American Commission of the Environment and Development (CCAD).",2 But most areas lack any

${ }^{2}$ La Comisión Centroamericana de Ambiente and Desarrollo (CCAD) is an intergovernmental organization supported by all Central American governments. Its purpose is to promote cooperation between Central American governments on issues of sustainable development, renewable energies, biodiversity, etc. The CCAD often acts as a main coordinator of funds and activities provided by governments, NGOs and international agencies interested in establishing environmental initiatives in the region. 
technical studies, which threatens to eliminate endangered areas and their biodiversity (Marineros and Gallegos 1998). Although an area may be designated protected, there is the distinct possibility that it is still treated as if it were not protected at all. Without proper support, inhabited protected areas are highly susceptible to deforestation, contamination, and destruction of flora and fauna.

\section{Southern Honduras}

Southern Honduras has become severely stripped of natural resources and eroded due to logging and unsustainable agricultural and ranching practices (Norsworthy and Barry 1994; Stonich 1993). In many areas in the southern department of Choluteca, this has occurred to the point of desertification. Wood is the main source of fuel, totaling 240,000 cubic meters of firewood for domestic consumption per year in the department of Choluteca alone (Oyuela 1995). Choluteca city, the capital of the department and its largest city with 120,000 people, is a commercial hub for firewood (Oyuela 1995; Stonich 1993). Oyuela (1995) estimates that 74 cubic meters of firewood are sold daily to locals who depend on firewood for cooking. Due to the lack of sustainable reforestation methods combined with high demand, people gather wood farther away and higher into the surrounding watersheds (Stonich 1993).

To supply the necessary amounts of firewood needed by the whole department, Oyuela (1995) estimates that 18,400 hectares of forest dedicated to firewood consumption need to be managed. Since 1975, 13 groups, both governmental and non-governmental, have carried out reforestation programs in the South Zone with little success. Since 1994, only 5,200 hectares have been reforested. In Oyuela's estimates, reforestation levels in Choluteca fall 13,200 hectares short of the number necessary to sustain wood consumption levels.

Rising population levels, extremely unequal land distribution, and unsustainable farming practices force people to live in the highlands of Choluteca. In Honduras, 4 percent of the landowners own 56 percent of the farmland, with only the poorest land left for subsistence and near-subsistence farmers (Norsworthy and Barry 1994). These areas tend to be the high altitude, drastically sloped mountain regions, where plots are generally 5 acres or less and not productive enough to sustain the poor farming families (Stonich 1993). In order to survive, farmers live in and cultivate even the headwaters of watersheds and protected areas. 
Protected area Cerro Guanacaure. Cerro Guanacaure contains a cluster of watershed headwaters located 15 kilometers southeast of Choluteca city. An area of about 2,000 hectares, it holds 7 stream sources, 12 villages, and an extensive flora/fauna population. ${ }^{3}$ The area consists of tropical dry forest and semi-dry forest (Peace Corps Honduras 1999) and provides approximately 30 percent of the domestic water for the city of Choluteca (Mayorga 1989). It is also the main contributor of water for the six municipalities that surround or lie within the area's boundaries. Moreover, it is the sole source of water for the 8,700 inhabitants living therein (Mayorga 1991; Peace Corps Honduras 1999). The COHDEFOR South Zone estimates that 65 villages benefit from Cerro Guanacaure's watersheds (personal communication). The name itself, an indigenous word, means, "hill filled with water."

In 1982, Honduras' president Calleges included Cerro Guanacaure in a presidential accord (\#1118-92), urging that 40 areas of environmental importance be protected under various categories ( $\mathrm{La}$ Gaceta 2000). Cerro Guanacaure was slated to be an Area of Water Production (Marineros 1998). However, as Calleges lacked legislative power, the area remained only unofficially protected until the year 2000, when congress finally officially declared it an "Area of Water Production".

Aside from being a potable water source, Cerro Guanacaure also provides an abundance of water to mangrove forests and shrimp farms in the Golf of Fonseca, some 30 miles from Cerro Guanacaure. This water helps maintain the ecological conditions vital for successful reproduction of aquatic life in the gulf (Peace Corps Honduras 1999). Because Cerro Guanacaure contains the headwaters of these watersheds, the very quality of the entire watershed depends on its environmental health and function, especially for the export of essential nutrients and nitrification processes (Peterson et al. 2001). Cerro Guanacaure is also a significant source of firewood and lumber for the city of Choluteca and its surrounding inhabitants. Cerro Guanacaure is one of the last remaining forested areas in the whole of the department of Choluteca. As stated by Mayorga (1991:2), "Here you find the only [mature] broad-leaf forest in the south of the country." In the 1970s small samples of unused tropical dry and tropical humid forest existed (Holdridge 1971), and presently shade coffee and fruit production abound. Coffee shade systems and forest

\footnotetext{
${ }^{3}$ This figure is disputed. The author has seen reported figures for the dimensions of Cerro Guanacaure ranging from 1,790 (reported by COHDEFOR in a Protected Area Information Brief) to 2,119 (reported by Oyuela 1995).
} 
provide refuge for many local birds, as well as some animals in danger of extinction. The whiteface monkey, white-tailed deer, the Agouti paca, and blue morpho butterfly have all been identified in Cerro Guanacaure (Peace Corps Honduras 1999). A biodiversity inventory organized by the author and a fellow Peace Corps Volunteer indicates that Cerro Guanacaure is an important area for migratory birds (Thorn 1998).

\section{Cerro Guanacaure: Did Proposition and Declaration Save Resources?}

Overall, many environmental aid groups have flocked to places like Cerro Guanacaure because of their soon-to-be protected status. In the global arena, the official declaration of natural space as protected brings with it the reassurance that funds will be spent wisely, and that natural spaces will be preserved "for the good of the international community" (Yearly 1996:56 in Pfeffer et al. 2001:384). Although not officially declared a protected area until the year 2000, Cerro Guanacaure has a longer history of globally-influenced natural resource management. Since its proposed declaration in 1982, it has hosted many environmental and developmental groups that introduced projects to help with conservation efforts. COHDEFOR ran a series of reforestation projects with the help (monetary and personnel) of international aid groups interested in preserving biodiversity and tropical forests. The Honduras Ministry of Water and Sanitation (SANAA) also organized several reforestation projects, mostly on the north-west side of the protected area, where the ministry owns lands that feed the northern watershed. Other Honduran groups, such as Honduran Institute of Coffee Growers (IHCAFE), continue to work with local coffee farmers and cooperatives, providing assistance with land conservation techniques and improved coffee harvests (Gareau 2004, 2008).

Most of the development projects introduced to Guanacaure are driven by external forces in both project design and organization (Gareau 2004, 2008). Reforestation projects, coffee improvement projects, and even the initial human habitation of the area were all organized by large firms and external aid groups that dictated how projects would function, the conditions of membership, and who could participate (Gareau 2004:102,104-105). Development projects in Guanacaure are largely geared towards the most market-savvy inhabitants (i.e., landlords). Traditionally, projects here engender an ethic of individualism and market exchange over and above community and/or natural resource management, which has contributed to large-scale 
failure in most projects. Consequently, very few people have benefited from natural resource management in Guanacaure, and those who have are not compelled to put back into the community any of the profits they acquire. Landlords depend strongly on the aid of non-local groups for road improvements and assistance with export markets, but the conditions of such aid, how it is used, is largely dictated by the nonlocal groups (Gareau 2004:105).

Through history of Cerro Guanacaure I could see whether local inhabitants perceived that the proposed declaration of Cerro Guanacaure contributed to an increase in conservation, a decrease in conservation, or did nothing at all. These questions were posed to 208 local inhabitants of Guanacaure in fixed format interviews and to several local leaders in in-depth interviews. I recognize that such questions deal with perceptions of change rather than "real" change. However, neither reliable data on natural resource management expenditures nor geographic information system data on forest cover exist. Therefore, the results here should be viewed with some caution. However, it would be unfair to dismiss the insights of local community leaders and other inhabitants regarding the success and failure of management efforts in which they played a significant role or which they observed. Consequently, the interviews help reveal whether park management has effectively stayed resource degradation from socioeconomic demand for these resources both inside the protected area and from the urban periphery.

\section{Method}

The interviews for this study were conducted in Spanish by myself and a fellow Peace Corps volunteer living at the time in two separate villages in Cerro Guanacaure from 1997 to 1999. We used a community-based approach comprised of a qualitative analysis, which is considered important to understanding rural areas and the positions of the local communities (Maxwell 1996), especially when no previous research has been conducted (Moris and Copesake 1993). Following Burawoy's “extended case method" (1998; 2000), we were then able to connect our ethnographic findings on perceptions of ecology and resource management to broader patterns found in globalization, in this case globalized natural resource management.

The first phase involved acclimating to the village communities in Cerro Guanacaure. We spent three months in Loc Cocos and Agua Fria, villages located in the nuclear zone of Cerro Guanacaure. From this location, we made frequent visits to all of the surrounding villages (12 
in all). In this way, the villagers learned about us and became accustomed to our presence. Ethnographers consider this a vital first step to reduce cultural barriers, to help the outside aid organizations gain an accurate understanding of the local area, and to gain an appreciation of the local perception of the protected area (Mosse 2002). As we were the first non-Hondurans to work and live in Cerro Guanacaure, this acclimation was invaluable to gain rapport and a more thorough understanding of the area (cf. Bernard 1994:chap. seven).

After three months, we considered that enough preliminary information had been gathered to begin a set of formal structured interviews. The initial intent was to interview ten men and ten women in each of the twelve villages (240 adults). Given the estimated population of Cerro Guanacaure (approx. 8,700), the author estimated that interviewing twenty people per village would provide an adequate sample of the area for the purposes outlined here. Due to time constraints, difficulty of access to most of the villages, and the lack of accurate village information, a non-random sample was deemed the most practical method and suitable for our purposes (Bernard 1994; Moris and Copesake 1993).

Because of difficulties just noted, as well as the occurrence of Hurricane Mitch, we interviewed only 208 people of the anticipated 240. Interviewees were selected as follows. We would walk to a particular village and start at the first house we encountered. If available, we would interview a male and female over the age of 18, preferably the heads of household. Therefore, home selection and the probability of a person being selected for the interview could not be determined prior this method, and was thus non-random. However, I believe that the sample is broad enough to build the arguments established here. These interviews were designed to gather information about the villagers' feelings toward their surrounding environment and their opinions about past projects affecting their village. Many villagers have keen insight into what may have caused project success or failure, whether projects achieved their assigned tasks (i.e., realized planting of trees, completion of latrine construction, etc.), since the villagers were either directly or indirectly involved with those projects.

Additionally, we conducted open-ended in-depth interviews with selected fuerzas vivas, or, local leaders, of the communities. This form of interview is very useful when heated political debates or contested local issues are concerns of the informant. In this case, the open-ended interviews led to discussions about the history of projects that informants would likely have been uncomfortable discussing in a formal setting (Bernard 1994:chap. ten). Moreover, the informants in this 
scenario were able to provide us with topics and information that we would probably not have requested. These interviews added to our understanding of the political and economic history of the protected area and to our understanding of how local leaders viewed the efficacy of aid organizations of projects implemented in Guanacaure.

In-depth interview findings. In-depth interviews with community leaders provided considerable evidence that inhabitants feel that environmental conservation projects failed to accomplish their goals. Community leaders reported that, in recent years, some effort has been made by the Honduran government to help the Cerro Guanacaure region. The Honduras Forestry Service (COHDEFOR) initiated several projects designed to alleviate soil runoff in small-scale agriculture, and thus impede the need for slash-and-burn into new areas, a practice that is illegal in Honduran protected areas like Cerro Guanacaure (see also Loker 2000; Pfeffer et al. 2001). Additionally, the Honduras Ministry of Water and Sanitation (SANAA) provided funding for building latrines and promoting the importance of latrine use for water quality maintenance in some villages (Mayorga 1989). But, as I have stated elsewhere (Gareau 2004, Gareau 2008), most development efforts have come from the Honduran Association of Coffee Producers (AHPROCAFE), a private organization that supports Honduran coffee farmers with reforestation with agro-silvicultural capacity (bananas for consumption, fuel-wood species intercropping with coffee plants), waterefficient coffee de-pulping technologies, and some road repair. ${ }^{4}$ These projects sometimes benefited the poorer community members indirectly, through food for work programs. But, on the whole, coffee projects benefited the coffee landowners almost exclusively.

Community leaders commented that most of these reforestation projects failed, even those geared toward coffee farmers. The issue here, some community leaders speculated, is that community members worked for food to maintain the tree nurseries that would eventually benefit coffee plantation owners. Many reforestation projects failed at the nursery stage due to inconsistent watering of nursery saplings during the dry season or lack of maintenance during heavy rains in the wet season. In short, resource conservation projects that benefited almost exclusively landlords were not a high priority for other community members involved in the projects.

It is important to note that this lack of success likely has very little to do with a dearth of interest in environmental improvements from

\footnotetext{
${ }^{4}$ For a full account of these projects and their history of failure, see Gareau 2004 and 2008 .
} 


\section{Table 1. Income and Land Wealth of Cerro Guanacaure and El Despoblado $(\mathrm{N}=\mathbf{2 0 8})$}

\begin{tabular}{lc}
\hline Monthly income (in Lempiras ${ }^{\mathbf{1}}$ ) & Percent $^{\mathbf{2}}$ \\
$0-500$ & 80 \\
$501-1000$ & 16 \\
$1000-2000$ & 1 \\
$1001-2000$ & 3 \\
$2001-4000$ & 1 \\
Size of land (in hectares) & \\
0 & 45 \\
$1-5$ & 34 \\
$6-10$ & 10 \\
$11-20$ & 10 \\
$21+$ & 1 \\
\hline
\end{tabular}

\footnotetext{
${ }^{1} \$ 1$ US $=\sim$ L14 at time of survey.

2 Percentages have been rounded.

Data taken from Gareau 2004:100.
}

project participants. In fact, the landless population and the population of landowners with very poor soil conditions in Cerro Guanacaure expressed strong interest in community projects that would improve their surrounding environment (Gareau 2008). Additionally, as I was involved with several reforestation projects during the time of the study, I am aware that both the landless and the inhabitants with poor land were often the very people involved in food for work reforestation projects. These are the social groups that require extra income to make ends meet, and they make up the bulk of the population (Table 1). Therefore, failure in reforestation projects likely has very little to do with lack of desire to improve the surrounding environment, as volunteers stressed interest in working on such projects in the future (Gareau 2008).

The source of failure, instead, appears connected to the poor construction of resource management projects. Reforestation projects were designed in a way that benefited the more powerful members of the community, such as landowners, and left the weak with little benefit. Such project designs heighten levels of social differentiation within the community, leaving those at or below the subsistence level with little incentive to see projects to their end. ${ }^{5}$ Reforestation project failure, here meaning the failed realized planting of trees, provided some income for participants, but may very well have exacerbated animosity between social groups (i.e., landowners versus the landless). One interview in particular

${ }^{5}$ I am grateful to an anonymous reviewer for stressing the importance of providing evidence of social differentiation and its connection to resource management failure in Cerro Guanacaure. 
revealed this possibility vividly. The community leader-a landowner of 40 hectares with maize and bean fields, a dozen cattle, two horses, a mule, and two of the few water holes in the village-discussed with me a few potential reforestation projects that COHDEFOR had proposed to initiate in several villages. The projects involved establishing tree nurseries and planting them on private land, such as that of this particular landowner. The landowner told me that the projects were doomed to failure, because similar efforts in the past had failed: "No one wants to plant trees on someone else's land. It is not a good idea. It leads to bad feelings in the community". Landowners may well regret the failure of conservation reforestation because these projects provide improvements to their own land.

The interview questions presented below demonstrate how community members view natural resource conservation efforts, and how they would have improved the design or function of projects were they consulted by the globalized environmental agencies on project design. Equally important is how interview questions can illustrate community notions of ecology and the importance of the ecosystem to their quality of life. Whereas the goal of the previous section was to illustrate how exogenously designed management schemes were not successful-due largely to their exacerbating effect on social differentiation-the goal of the next section is to illustrate how community members as a whole observe natural resource degradation, and how local involvement in management is a valid pursuit, not only to impede the heightening of the social differentiation of power described above, but also because of the locally constituted ecological values held by community members.

Fixed format interviews and analysis. To understand how community members viewed environmental conservation efforts in Cerro Guanacaure since its proposed declaration and the initiation by environmental/aid agencies to conserve its natural resources, we asked local inhabitants some specific questions. For example, we asked how the state of their personal watershed had changed, if at all, over the past five years. We first asked, "What is the state of vegetation of your personal watershed right now?" Then, we followed up by asking: "What was the state of vegetation of your watershed five years ago?" We chose a fiveyear period because, (1) this would have allowed projects initiated in 1982 to have taken effect; and (2) it is assumed to be well within the memory of all interviewees. ${ }^{6}$

\footnotetext{
${ }^{6}$ We used the term microcuenca, which means "micro watershed", to discuss these questions. We made clear to the informants that we were interested in the area surrounding their village's water source exclusively. Follow-up questions then referred to the state of forestation of Cerro Guanacaure as a whole.
} 


\section{Table 2. Feelings about the State of the Surrounding Environment}

\begin{tabular}{lc}
\hline State of vegetation today in personal watershed & Percent \\
Well forested & 22 \\
Partly forested & 40 \\
Very deforested & 36 \\
State of vegetation five years ago & 29 \\
Well forested & 45 \\
Partly forested & 24 \\
Very deforested & 45 \\
Level of forestation in all of CG* now compared to the past & 39 \\
Some less to much less deforested now & 13 \\
Some more to well-forested now & 48 \\
The same level & 27 \\
Bird population 5-10 years ago compared to present & 76 \\
A lot less to less now & 16 \\
Same amount & \\
Mammal population 5-10 years ago compared to present & 65 \\
A lot less to less now & 31 \\
Same amount & \\
Reptile population 5-10 years ago compared to present & 41 \\
A lot less to less now & 48 \\
Same amount & \\
Aquatic animal population 5-10 years ago compared to present & A lot less to less now \\
Same amount &
\end{tabular}

* Cerro Guanacaure.

Source: 208 interviews conducted from 1997-1999.

Our findings (in Table 2) show that out of the 208 respondents, 36 percent reported their watershed as "very" deforested at present, and 40 percent reported it as "partly" forested. Only 22 percent said that their watershed was "well" forested at present. In contrast, only 24 percent reported that their watershed was "very" deforested five years ago, and 45 percent said that it was at least "partly" forested five years ago. The remaining 29 percent stated the watershed was "well" forested five years ago. These results show that over a five-year period the majority of local inhabitants of Guanacaure believe the forestation of their respective watersheds has decreased.

To complement this aspect of the analysis, we then asked about the ecology of Guanacaure in general. We asked, "How is Cerro Guanacaure forested now compared to the past?" The answers reveal similar sentiments about the efficacy of natural resource conservation efforts. Of those interviewed, 45 percent said that Guanacaure was forested "much less" or "some less" when compared to the past. However, 39 percent said Guanacaure was forested "some more" or "well forested" now, and 13 percent that it was forested "the same" as before. In this case, almost half of those interviewed stated that 
Guanacaure is in a worse condition at present than in the past, and a further 13 percent think nothing has happened (See Table 2).

As biodiversity is an important element in the justification of natural resource conservation, we asked questions about certain types of animal populations in Guanacaure. We asked whether populations of birds, mammals, reptiles, and aquatic animals had increased or decreased over the last 5-10 years. We asked about each animal type separately to avoid confusion. When asked, "How many birds are there compared to 5-10 years ago?" 48 percent of those interviewed said there are either "a lot less" or "less" birds now than in the past; 27 percent said that there was the same amount of birds. When asked the same question about mammals, 76 percent said there were "a lot less" or "less" mammals at present. Here, 16 percent that it was the same amount. For reptiles, 65 percent said there were "a lot less" or "less," while for aquatic animals 41 percent responded that there were "a lot less" and 48 percent said there were "the same amount" (see Table 2).

These results show that the inhabitants believe the natural environment of Guanacaure has been depleted over the years. Forest cover, watershed vegetation, and all types of animal species are observed to be in decline or unchanged status. This is not uncommon in Third World countries, as studies by Pfeffer et al. (2001) and others (e.g., Liu et al. 2001) inform us. Often, the integration of outside knowledge with local ideas leads to conflict and discord that was never intended (Loker 2000). Part of the reason is due to a lack of coherence between the groups involved in the conservation schemes. Local ideas will likely include concern for human survival and livelihoods, whereas non-local ideas may stress preservation of resources over sustainable use of resources. Whatever the case, a large reason for failure to integrate the interests of local communities is due to the fact that locals are seldom, if ever, involved in a tangible way in the decision-making process of protected area declaration and management. This is the case in Guanacaure as well.

Table 3 shows a qualitative assessment of another interview question, "What would you have done differently to improve the project?" Answers to the question were diverse and informative, and reveal some inhabitants' desire for greater project participation. As shown in Table 4, only 15 percent of respondents answered outright that they believed more community participation was necessary in projects. However, the rich array of responses to the "project" question (a selection of which can be found in Table 3) also point to respondents wanting more community participation. Whether the responses depict discontent with the amount of training received, the type of project 


\section{Table 3. Selected Responses to Survey Question: "What would you have done differently to improve the project?"1}

"It didn't function because of the mayor (his fault)",

"They didn't complete the project like they said they would"

"We lacked capacitación (training)",

"Would have trained the people (locals)"

"More capacitación"

"They didn't arrive (return) after the greeting day"

"More discussion, capacitación with the community"

"The people didn't want the project"

"I would have planted more (trees)"

"To know the culture (on the part of the agencies involved)"

"Would have finished the project"

"A project for woman"

"They didn't finish the project"

"Help from the mayor"

"Finish the project"

"The institutions do not listen to advice from the community. Things have to be done their way because they are the "experts",."
"More projects to the "top" (to El

Despoblado)

"Didn't work"

"Latrine project"

"Have projects for the rest of the people"

"Have the projects come to the rest of the people"

"(Tree) nurseries closer to the water"

"A water project"

"They have not returned"

"More communication with the group"

"The people are not united"

"Don't know"

"Más aca" (more projects "here")

"More discussion with the community"

"They didn't arrive (return) after the greeting day"

"Seguimiento (continuance or sustainability) of the project',

"The project involved only part of the community",

Source: 208 interviews conducted from 1997-1999.

${ }^{1}$ Items in parentheses are included for clarity.

introduced, or a lack of communication between community members and project managers, the general implication is that the respondents are dissatisfied with their level of involvement in the decision-making process about resource management (Table 3).

\section{Ecological Values amid Local Interests}

Lack of local participation and concomitant natural resource degradation in inhabited protected areas has led some researchers to believe that local peoples hold a (utilitarian) worldview incompatible with First World notions of environment and ecology. I argue against this belief. Local peoples do indeed hold an ecological view of their surroundings. This is not to say that local peoples hold an ecological worldview that is the same as that of non-locals, but that it is one that is compatible with many globalized ecological views.

As discussed above, unsuccessful natural resource management is partially due to the various forms of resistance employed to survive, and 
to issues of power and social differentiation. Local peoples feel threatened by outside interference when it conflicts with their basic needs. When faced with the choice of viewing a natural resource as wilderness or as a potential to aid in their families' subsistence, they will view it as a potential for subsistence. Pfeffer et al. (2001) illustrated this by showing local inhabitants of Azul Meambar National Park in Honduras pictures of wilderness at various states of forestation. Local inhabitants in the park often expanded the interpretation of what constituted a usable resource, due potentially to the regulations that restrict certain activities (Pfeffer et al. 2001:396-397). However, our interviews here also show that this does not mean that locals view natural resources simply in an individualistic and utilitarian way. They also see their natural space in an ecological and sociocultural way.

Additional interview questions further explored what is important about living in Cerro Guanacaure. Sixty-three percent answered "the climate" or a combination of "the climate" with "the water," "the tranquility," "the soil," or "the vegetation." Interviewees often added comments such as el agua es más fresca aqui que en Choluteca ("the water is cooler here than in Choluteca [city]"), or nuestro lugar tiene más naturaleza ("our place has more natural environment"). When commenting on the climate, interviewees would remark el clima es mejor acá que en otros lugares, más fresco ("the climate is better here than in other places, cooler').

A general sentiment exists that the inhabitants felt fortunate to live in a place that contained fresh water and a climate comparatively cooler than that found in other parts of Choluteca. Twenty-five percent felt that being from the area and the culture in which they lived was the most important aspect of living in Guanacaure: "I was born here;" “"our church is here;" "there are respectable people here;" "I am accustomed to being here;" "the community;" or "the culture" (Table 4).

I do not think the questions above were confused with one that would have had a stronger possibility of being influenced by outside interpretation, namely, the reason why Cerro Guanacaure is officially protected. We asked this question in the form of: "Why do you think it is important to protect Cerro Guanacaure?" One half of those interviewed answered, "to protect the water." Whereas all but one person had an answer for the question regarding what was most important about living in Guanacaure, 18 percent of those asked about the reason to protect Guanacaure did not have an answer. Likewise, when asked how well they understood the municipal laws pertaining to the area, 85 percent of the interviewees reported not knowing the laws 


\section{Table 4. Questions Related to the Importance of Cerro Guanacaure and Community Participation (in Percent)}

\begin{tabular}{lr}
\hline What is most important about living in Cerro Guanacaure? \\
Climate, or combination of climate, water, tranquility, soil quality, or vegetation & 63 \\
Born in the area, and the culture is important & 25 \\
Why is it important to protect Cerro Guanacaure? & 50 \\
To protect the water & 18 \\
Protect the trees & 7 \\
For a healthy environment & 18 \\
Don't know & 85 \\
Do you understand the municipal laws of Guanacaure? & \\
Not at all, or only a little & 15 \\
What would you have done different with the projects? & 80 \\
More community participation & 81 \\
Other responses (see Table 3) & 7 \\
Would you rather stay in your community or move to a new location? & 13 \\
Stay & \\
Leave & \\
Don't know &
\end{tabular}

Source: 208 interviews conducted from 1997-1999.

at all, or only knowing them "a little." This is important, because the municipal laws were the source of resource protection prior to the official declaration of Guanacaure at the national level in 2000 (see Table 4). Responses to this question were also very much related to ecological concerns with their livelihoods, where 18 percent stated the need to protect the trees, and another 7 percent reported its connection to a healthy environment (Table 4). Related to this question were general comments such as "It doesn't rain here like it used to, so it is difficult to grow enough crops like before" or, "There no longer exists good land to plant on" or, "Cerro Guanacaure must be protected for the health of the area". Interviewees recognized that while their own actions were contributing to environmental degradation, water shortages, etc., they also had to make ends meet. Despite these difficulties, most inhabitants interviewed want to remain in their communities: 81 percent would rather stay than leave their communities (Table 4).

The interview questions listed above reveal the ecological concerns held by inhabitants of Cerro Guanacaure. Local communities, however, are seldom a part of the decision making process and, subsequently, often do not understand the global environmental agenda. In the case of Guanacaure, local ecological concerns have been ignored, and yet the laws attached to the area have also been ineptly enforced and explained to the inhabitants. With 85 percent of respondents not 
understanding the laws of protection, more participation from inhabitants seems imperative to improve understanding and resource management design. In this case, both local ecological values and global notions of protection have been misplaced. The result has been an almost certain loss in species biodiversity and forest cover.

\section{Conclusion}

Recent research on natural resource management shows that local worldviews often conflict with the environmental view held by global environmental and governmental groups involved in protected area declaration and management. Locals often react by utilizing a form of resistance that allows them to legitimate their own survival. Although this might be true, it is important to emphasize that some inhabitants of protected areas hold concerns that parallel the ecological values of many global environmentalisms. Failure in conserving natural resources is a sign that exogenously designed park regulations, coupled with a lack of understanding of socially differentiated local conditions, do not provide a feasible alternative to resource degradation.

We must be careful of how such a conclusion could be used to characterize efforts made by people on the brink of survival. That people living in protected areas are interested in surviving, and often have to do so with incompatible First World ecological values imposed upon them, must not obscure the ecological considerations that many of them give to their resources, their "natural space." This paper shows that people living in very difficult conditions often view their resources to be much more than simply a means to a tangible end. In fact, projects that failed to lead to the realized planting of trees, or to the reforestation of watersheds, appear to be much more related to issues of power and social differentiation-of landowners benefiting from projects more than the landless and of projects designed without any understanding of differentiated local socionatural conditions-than to a lack of ecological concerns. Indeed, ecological concerns appear quite embedded within local concerns to survive for the most impoverished people.

Fixed format and in-depth interview responses demonstrate that the inhabitants of Cerro Guanacaure have a strong understanding of: (1) the history of unsuccessful development, likely exacerbated by project designs that disregard issues of power and social differentiation; and (2) the ecological and sociocultural importance of Cerro Guanacaure, even while being unaware of global environmental agendas expressed through municipal protected area laws. Clearly, the inhabitants 
understand why Guanacaure is important for their livelihoods, both for the sociocultural ties and the ecological conditions embedded therein.

What remains deleterious is that the inhabitants are required to degrade their homeland in order to survive. Local peoples, especially the landless and otherwise powerless peoples, are forced to participate in an environmentalism that does not include their own ecological concerns or consider their circumstances. By designing national parks without the involvement of local people, without gaining consciousness of issues of power and social differentiation, and without providing feasible alternatives to resource degradation, natural resources will continue to disappear and livelihoods to remain impoverished in Cerro Guanacaure and other places subject to similar brands of global environmentalism.

\section{References}

Bernard, H.R. 1994. Research Methods in Anthropology: Qualitative and Quantitative Approaches. Walnut Creek, CA: AltaMira Press.

Brandon, K. 1998. "Perils to Parks: The Social Context of Threats." Pp. 1-23 in Parks in Peril: People, Politics, and Protected Areas, edited by K. Brandon, K.H. Redford, and S.E. Sanderson. Washington, D.C.: Island Press.

Brechin, S.R., P.R. Wilshusen, C.F. Fortwangler, and P.C. West. 2002. "Beyond the Square Wheel: Toward a More Comprehensive Understanding of Biodiversity Conservation as Social and Political Process." Society and Natural Resources 15:41-64.

Buck, L., C. Geisler, J. Schelhas, and E. Wollenberg, eds. $2 \overline{001 . ~ B i o l o g i c a l ~ D i v e r s i t y: ~}$ Balancing Interests through Adaptive Collaborative Management. Boca Raton, FL: CRC Press.

Burawoy, M. 1998. "The Extended Case Method.” Sociological Theory 16:4-33.

Burawoy, M., ed. 2000. Global Ethnography: Forces, Connections and Imaginations in a Postmodern World. Berkeley, CA: University of California Press.

Christiansen, S. and E. Dinerstein. 2001. "Ecoregional Perspectives in Conservation: Recent Lessons and Future Directions." Pp. 51-68 in Biological Diversity: Balancing Interests through Adaptive Collaborative Management, edited by L.E. Buck, C.C. Geisler, J. Schelhas, and E. Wollenberg. Boca Raton, FL: CRC Press.

Cronon, W. 1995. "The Trouble with Wilderness; or, Getting Back to the Wrong Nature." in Uncommon Ground: Toward Reinventing Nature, edited by William Cronon. New York: W.W. Norton \& Company.

Ebrahim, A. 2003. NGOs and Organizational Change. Cambridge. New York: Cambridge University Press.

Escobar, A. 1996. "Constructing Nature: Elements for a Poststructural Political Ecology." Pp. 46-68 in Liberation Ecologies: Environment, Development, and Social Movements, edited by R. Peet and M. Watts. New York: Routledge.

Gareau, B.J. 2004. "Use and Exchange Value in Development Projects in Southern Honduras." Capitalism, Nature, Socialism 15:95-110.

- 2008. "Class Consciousness or Natural Consciousness? Socionatural Relations and the Potential for Social Change: Suggestions from Development in Southern Honduras." Rethinking Marxism 20:forthcoming.

Geisler, C. 2001. "Adapting Land Reform to Protected Area Management in the Dominican Republic." Pp. 99-122 in Biological Diversity: Balancing Interests through Adaptive Collaborative Management, edited by L. Buck, C. Geisler, J. Schelhas, and E. Wollenberg. Boca Raton, FL: CRC Press. 
Guha, R. and J. Martinez-Alier. 2000. Varieties of Environmentalism: Essays North and South. London: Earthscan.

Holdridge, L.R. 1971. Forest Environments in Tropical Life Zone: A Pilot Study. New York: Pergamon.

Jackson, J.T. 2005. The Globalizers: Development Workers in Action. Baltimore: Johns Hopkins University Press.

La Gaceta: Diario Oficial de la Republica de Honduras. 2000. Poder Legislativo- Decreto numero 29,076. Tegucigalpa: La Republica de Honduras.

Lipschutz, R. and J. Mayer. 1996. Global Civil Society and Global Environmental Governance. Albany, NY: SUNY Press.

Liu, J., M. Linderman, Z. Ouyang, L. An, J. Yang, and H. Zhang. 2001. "Ecological Degradation in Protected Areas: The Case of Wolong Nature Reserve for Giant Pandas." Science 292(5514):98-101.

Loker, W.M. 2000. "Sowing Discord, Planting Doubts: Rhetoric and Reality in an Environment and Development Project in Honduras." Human Organization 59:300-10.

Margerum, R.D. 2001. "Organizational Commitment to Integrated and Collaborative Management: Matching Strategies to Constraints." Environmental Management 28:421-31.

Marineros, L. and F. Martínez Gallegos. 1998. Guía de Campo de los Mamíferos de Honduras. Tegucigalpa: Instituto Nacional de Ambiente y Desarrollo.

Maxwell, J.A. 1996. Qualitative Research Design: An Interactive Approach. Thousand Oaks, CA: SAGE Publications.

Mayorga, J.J. 1989. "Water Quality of Low Stream Flows on the Cerro Guanacaure Watershed." PhD dissertation, School of Renewable Natural Resources, University of Arizona.

—. 1991. "Contaminación de Aguas en la Cuenca del Cerro Guanacaure." Choluteca, Honduras: Peace Corps- Honduras.

McMichael, P. 2003. Development and Social Change: A Global Perspective. London: Pine Forge Press.

Moris, J. and J. Copesake. 1993. Qualitative Enquiry for Rural Development: A Review. London: Intermediate Technology Publications.

Mosse, D. 2002. "The Making and Marketing of Participatory Development." in Participatory Action Research and Participation in Development. Uppsala University: Sweden.

Norsworthy, K. and T. Barry. 1994. Inside Honduras: The Essential Guide to its Politics, Economy, Society and Environment. Albuquerque, NM: Inter-Hemispheric Education Resource Center Press.

Oyuela, D.O. 1995. "Los Recursos Forestales y La Vida Silvestre en la Zona Sur de Honduras." Siguatepeque, Comayagua, Honduras: National School of Forestry Science-ESNACIFOR, Department of Investigation of Applied Forestry.

Peace Corps Honduras. 1999. "Investigación Programática de Sitio y Asignación de Voluntario." Tegucigalpa: Peace Corps Honduras.

Peet, R. and M. Watts. 1996. "Liberation Ecology: Development, Sustainability, and Environment in an Age of Market Triumphalism." Pp. 1-45 in Liberation Ecologies: Environment, Development, Social Movements, edited by R. Peet and M. Watts. New York: Routledge.

Peluso, N.L., C.R. Humphrey, and L.P. Fortmann. 1994. "The Rock, the Beach, and the Tidal Pool: People and Poverty in Natural Resource Dependent Areas.' Society and Natural Resources 7:23-38.

Peterson, B.J., W.M. Wollheim, P.J. Mulholland, J.R. Webster, J.L. Meyer, J.L. Tank, E. Martí, W.B. Bowden, H.M. Valett, A.E. Hershey, W.H. McDowell, W.K. Dodds, S.K. Hamilton, S. Gregory, and D.D. Morrall. 2001. "Control of Nitrogen Export from Watersheds by Headwater Streams."' Science 292:86-89.

Pfeffer, M., J.W. Schelhas, and L.A. Day. 2001. "Forest Conservation, Value Conflict, and Interest Formation in a Honduran National Park."' Rural Sociology 66:382-402. 
Sachs, W., ed. 1993. Global Ecology: A New Arena of Political Conflict. New Jersey: Zed.

Selznick, P. 1984. TVA and the Grassroots: A Study of Politics and Organization. Berkeley, CA: University of California Press.

Slater, C. 1995. “Amazonia as Edenic Narrative.' Pp. 114-31 in Uncommon Ground: Toward Reinventing Nature, edited by W. Cronon. New York: W.W. Norton \& Company.

Stonich, S.C. 1993. I am Destroying the Land! The Political Ecology of Poverty and Environmental Destruction in Honduras. San Francisco, CA: Westview Press.

Swyngedouw, E. 1999. "Modernity and Hybridity: Nature, Regeneracionismo, and the Production of the Spanish Waterscape, 1890-1930.' Annals of the Association of American Geographers 89:443-65.

Thorn, S. 1998. "Fauna Inventory of Cerro Guanacaure, Choluteca." Department of Biology. Universidad Autónomo de Honduras (UNAH), Tegucigalpa. Unpublished manuscript.

Watts, M., and N.L. Peluso, eds. 2001. Violent Environments. Ithaca: Cornell University Press.

Walton, J. 1992. Western Times and Water Wars: State, Culture, and Rebellion in California. Berkeley, CA: University of California Press.

Yearly, S. 1996. Sociology, Environmentalism, Globalization: Reinventing the Globe. Thousand Oaks, CA: Sage. 